\title{
ARABISMOS EUROPEUS NO PORTUGUÊS BRASILEIRO
}

\author{
Francisco Barroso de Sousa \\ Samantha de Moura Maranhão
}

RESUMO

Este trabalho sobre empréstimos árabes no português brasileiro tem por objetivo conhecer usos regionais da herança ibérica, a partir da marcação diassistêmica documentada no Léxico Português de Origem Árabe (VARGENS, 2007). Analisa a estrutura dos arabismos, bem como classes de palavras e campos semânticos que integram.

PALAVRAS-CHAVE: arabismos ibéricos; português brasileiro; lexicografia.

\section{Introdução}

ste estudo sobre arabismos portugueses teve por objetivo conhecer empréstimos árabes do português europeu que, no português brasileiro, adquiriram novas acepçóes e usos, constituindo a sua questão norteadora "A lexicografia nacional documenta arabismos europeus como marcação diassistêmica de brasileirismos?".

A hipótese testada foi a de que os arabismos trazidos pelo colonizador lusófono eram arabismos ibéricos medievais, devidamente integrados ao sistema lexical da língua portuguesa, o que possibilitou novos usos, no Brasil, em formas compostas e derivadas, em diferentes classes de palavras, apresentando, ainda, novas acepçōes.

Fundamentaram este estudo autores que abordaram o contato de línguas (BLOOMFIELD, 2005; LÜDTKE, 1974; FREITAS, RAMARILO E 
SOALHEIRO, 2002) e, especificamente, o contato português-árabe (MACHADO, 1997; NEUVONEN, 1951; VIGUEIRA MOLINS, 2002), além de dicionários gerais (MICHAËLIS, 1998; AURÉLIO, 1999; HOUAISS E VILLAR, 2010) e especializados (CORRIENTES, 2003; VARGENS, 2007).

\section{Contato de línguas e integração de arabismos na língua portuguesa}

O empréstimo linguístico se caracteriza pela adoção de traços que se diferem do tradicional de uma língua (BLOOMFIELD, 2005, p. 444), motivada pela interação de falantes de línguas maternas distintas em situações específicas ou no convívio intenso (CÂMARA JR, 1988, p. 104). $\mathrm{O}$ manejo das duas línguas pelos falantes bilíngues, com domínios distintos do sistema estrangeiro, promove as interferências, que se evidenciam em todos os planos da língua - no léxico, na fonética, na semântica, na morfologia, na sintaxe -, verificando-se, nos dois últimos, influência maior e mais profunda, em decorrência de contato mais intenso ou prolongado (LÜDTKE, 1974, p. 283).

De acordo com o tipo de contato verificado entre as línguas, classificam-se os empréstimos como: a) intimos, oriundos de línguas que são substrato, adstrato ou superstrato da língua importadora, e que cobrem campos semânticos correlacionando a geografia de contato e os povos envolvidos; b) culturais, resultantes de contato a distância, no tempo ou no espaço (BLOOMFIELD, 2005, p. 461; CÂMARA JR., 1988, p. 105, 111 ; VARGENS, 2007, p. 35).

Nos conceitos de estrangeirismo e empréstimo, constata-se uma oposição pautada no estágio de integração do vocábulo à estrutura (fonológica, morfossintática e semântica) da língua que o absorve: percebe-se mais facilmente a estrutura de vocábulo estrangeiro naquele, ao passo que, neste, o radical estrangeiro, adaptado, frequentemente tem irreconhecível a sua origem exterior à comunidade linguística que o adotou (MACHADO, 1997, p. 245; IORDAN, MANOLIU, 1989, p. 63).

Pautados em estudo da integração de anglicismos ao português europeu, Freitas, Ramilo e Soalheiro (2002, p. 371) descrevem o processo de assimilação de estrangeirismos em três fases, caracterizadas pelo tipo de transformação 
(imediata, progressiva ou integração) sofrida pelo vocábulo, a cada uma das quais correspondendo fenômenos fonológicos, morfossintáticos, semânticos e gráficos específicos.

Quando definitivamente integrados ao sistema lexical da língua importadora, os vocábulos deixam de ser estrangeirismos, aproximando-se formalmente dos vocábulos já listados no seu léxico. Caracterizam-se, portanto, pela: 1. estabilização fonológica, com a fixação do acento; 2. plena integração morfossintática, com gênero e plural fixados; 3 . integração no sistema morfológico da língua, verificando-se a possibilidade de derivação; 4. polissemia, com tendência para extensão, restrição ou modificação do significado da forma original; 5. atestaçâo lexicográfica normatizada (FREITAS, RAMILO, SOALHEIRO, 2002, p. 379-380).

A presença de arabismos em línguas neolatinas, principalmente no espanhol e no português, deve-se, fundamentalmente, aos empréstimos ocorridos durante a Idade Média, com a presença de árabes e de arabófonos, como os moçárabes, mudéjares e mouriscos por toda da Península Ibérica, notadamente em Alandalus (VIGUEIRA MOLINS, 2002, p. 50).

Conforme Vigueira Molins (2002. p. 50), com menor frequência, introduziram-se arabismos nas línguas peninsulares, e particularmente no português, com o advento das grandes navegaçóes e a consequente expansão ultramarina de Portugal e Espanha. Teyssier (2001, p. 22) também apresenta outros percursos realizados por termos de origem árabe até chegarem à língua portuguesa, como a Itália e, muito posteriormente, os continentes africano e asiático.

Entretanto, apenas Vargens (2007, p. 35) aborda a introdução de arabismos no português brasileiro por intermédio de oeste-africanos islamizados e de imigrantes sírio-libaneses. Esta via brasileira absorveu tanto palavras e expressóes relacionadas com o culto religioso dos escravos muçulmanos, como àquelas ligadas à culinária dos imigrantes sírios e libaneses distribuídos por todo o território brasileiro.

A fraseologia tem por objeto expressóes cotidianas de uma comunidade de fala, a exemplo de provérbios e de sentenças populares. O seu principal objeto de estudo é a unidade fraseológica, também dita frase feita, expressão fixa, etc. Trata-se das combinaçóes de palavras com alto grau de fixação, formada por, no mínimo, dois itens (DOUMA, 2012, p. 10, 15). 


\section{Metodologia}

Para verificar a ocorrência de arabismos ibéricos com usos específicos no Português Brasileiro, recorreu-se ao Léxico Português de Origem Árabe (VARGENS, 2007).

A coleta de dados se deu manualmente, mediante os seguintes critérios: a) serem os termos herdados do português europeu, com a consequente exclusão daqueles introduzidos no português brasileiro por meio de oeste-africanos islamizados e de imigrantes sírio-libaneses, salvo se constituídos por elemento previamente integrante do sistema lexical português, como arroz-de-hauçá; b) trazerem alguma acepção particular no português brasileiro, tema deste estudo, o que se verificou mediante análise da marcação diassistêmica indicada nos verbetes; c) serem, do ponto de visto morfológico, formas simples, compostas, derivadas ou unidades fraseológicas constituídas por elemento árabe; d) serem, no que respeita às classes de palavras, integrantes de qualquer uma destas, desde que observado o critério "a"; e) integrarem o vocabulário da língua comum ou a terminologia de alguma profissão em particular; f) integrarem qualquer campo semântico.

Da aplicação dos critérios apresentados resultou a identificação de 274 brasileirismos pautados no emprego de arabismos herdados da colonização portuguesa no continente sul-americano. Como alguns sáo polissêmicos, a sua distribuição por campos semânticos demandou uma recontagem desses itens, o que resultou no total de 300 unidades lexicais e/ou fraseológicas.

Os dados são apresentados, na seção seguinte, na forma de um pequeno glossário de arabismos do português brasileiro, cujos verbetes, reproduzindo o mais fielmente possível os da fonte, trazem os itens lexicais levantados, informaçóes gramaticais e sua acepçáo ou acepçóes na variedade americana da língua portuguesa. Informaçóes complementares acerca de usos dos arabismos do português brasileiro, como a região, variedade ou norma linguística em que ocorrem também são indicadas, se disponíveis. Em rodapé, apresentam-se informaçóes complementares sobre os referentes designados pelos arabismos estudados, em geral colhidas no Dicionário Houaiss da Lingua Portuguesa (HOUAISS; VILLAR, 2010), por se tratar de dicionário enciclopédico, rico em informaçóes tanto linguísticas quanto extralinguísticas, ou na própria fonte, o Léxico Português de Origem Árabe (VARGENS, 2007). 
Empregaram-se as seguintes abreviaturas nos verbetes: adj. adjetivo; adj. $2 \mathrm{~g}$. adjetivo de dois gênero; adj. 2g.2n. adjetivo de dois gêneros e de dois números; adj. e part. adjetivo e particípio; ant. bras. Antigo brasileirismo; fam. Familiar; fig. sentido figurado; gír. Gíria; loc. adv. locução adverbial; lus. Lusitanismo; part. particípio; pop. Popular; s.2g. substantivo de dois gêneros; s.f. substantivo feminino; s.m. substantivo masculino; u.f. unidade fraseológica; v.t.d. verbo transitivo direto; v.t.d. e int. Verbo transitivo direto e intransitivo; v.i. verbo transitivo indireto; v.int. verbo intransitivo; var. variante.

\section{Arabismos do português brasileiro: a herança europeia "climatada"}

Os arabismos do português europeu que no Brasil adquiriram significados regionais, segundo marcaçóes diassistêmicas encontradas no Léxico Português de Origem Árabe (VARGENS, 2007) são:

Abelmosco - s.m. Quiabo-de-cheiro.

Açafrão da terra - s.m. Planta da família das zingiberáceas, cujos frutos, em forma de cápsulas, são comestíveis e medicinais; açafreiro; açafroeira; açafroeira-da-índia; açafroeiro-da-índia.

Acica - s.f. Bolso.

Açoita-cavalo - s.m. Nome de árvores do gênero luhea, da família das tiliáceas, cuja madeira serve para edificações e imobiliário.

Açoiteira - s.f. 1. Extremidade da rédea com que o cavaleiro alerta o animal. 2. Chicote curto usado no Rio Grande do Sul. Var. açouteira.

De açoite - loc. adv. Repentinamente, subitamente.

Açougue - s.m. 1. fig. Prostíbulo; 2. fig. Local utilizado para encontros amorosos, geralmente clandestinos.

Açucena-branca - s.f. Planta de flores brancas e perfumadas; copo-de-leite.

Açucena-d'água - s.f. Planta de flores alvas e perfumadas, que serve para a ornamentação.

Açucena-do-campo - s.f. Tipo de açucena existente nos campos dos planaltos do sul e do centro do Brasil.

Açucena-do-rio - s.f. Carapitaia, erva ornamental, de flores brancas, de bulbo pequeno e comestível. 
Açude - s.m. 1. NE. Local onde o lavrador planta, à medida que baixa o nível da água. 2. Lago onde se represa a água.

Adufe - s.m. Antigo pandeiro quadrado, de madeira, com dois tampos de pergaminho. Var. adufo.

Alcaguete - s.m. Espião de polícia; aquele que transmite informaçóes sigilosas; dedo-duro. Var. pop. caguete.

Alcaguetagem - s.m. Ato ou efeito de alcaguetar.

Alcaguetar - v.t.d. e int. Delatar; denunciar.

Alcaide - s.m. 1. Objeto fora de uso. 2. Indivíduo muito feio. 3. Cavalo muito ruim, pangaré.

Alcateia - s.f. $\mathrm{Na}$ terminologia da marinha, grupo de submarinos em operação conjunta.

Alcatifa - s.f. Planta rasteira, trichospira menthoides.

[Alcatra] u.f. Andar nas alcatras. - Montar a cavalgadura sem sela, selim ou arreio; montar em pelo. Var. alcatre.

[Alcatra] u.f. Bater a alcatra na terra ingrata. - RS. pop. Falecer, morrer. Alcatruzado - adj. Tristonho, melancólico.

Alcooleiro - adj. De ou referente ao álcool ou que o produz.

Aldeia - s.f. 1. Povoação de índios. 2. BA. Terreiro, nos candomblés de caboclo. 3. RS. Vila de casas de soldados, situada perto dos quartéis.

Aldeado - adj. e part. 1. Tribo(s) indígena(s) sob a direção de religiosos ou leigos. 2. Local onde são alojados presidiários.

Alecrim-do-mar - s.m. BA. Denominação usada para várias plantas das famílias das compostas, labiadas e verbanáceas.

Aletria - s.f. Manjuba. ${ }^{1}$

Alfaiate - s.m. Tiziu, ave sul-americana.

Alfanje - s.m. Gadanha. ${ }^{2}$

Alfavaca-do-campo - s.f. Segurelha. ${ }^{3}$

Alforje - s.m. gír. Nariz grande e chato.

Algema - s.f. gír. Pulseira.

1 De acordo com Houaiss (2001), trata-se de peixe da família dos engraulídeos, especialmente os gêneros Anchoviella e Anchoa.

2 Houaiss (2001) apresenta 02 acepções para gadanha, "concha funda de cabo comprido" e "foice de cabo comprido para cortar feno".

3 Haste pela qual passa o ferro que segura a mó inferior dos engenhos de moer grãos, de acordo com Houaiss (2001). 
Algodão-bravo - s.m. Designação de duas plantas brasileiras, da família das malváceas e das convolvuláceas.

Algodão-cravo - s.m. Butuá-de-corvo. ${ }^{4}$

Algodão-da-praia - s.m. Planta brasileira, da família das malváceas, de flores amarelas, utilizadas na ornametação; algodoreiro-da-praia.

Algodão-de-açúcar - s.m. Algodão-doce.

Algodão-do-brejo - s.m. Fanfã. ${ }^{5}$

Algodão-do-mato - s.m. Butuá-de-corvo; algodoeiro-do-mato.

Algodãorana - s.f. Planta amazonense, da família das malváceas Pavonia paniculata, utilizada na indústria têxtil.

Algodoreiro-do-campo - s.m. Butuá-de-corvo.

Algodoim - s.m. Algodãozinho. ${ }^{6}$

Almécega - s.f. Goma. ${ }^{7}$

Almíscar - s.m. NE. Cheiro de peixe.

Almofadinha - s.m. Homem que se excede ao se vestir.

Almofadismo - s.m. 1. Elegância exagerada. 2. Modos e atitudes de almofadinha.

Alqueire - s.m. Medida agrária; em Minas Gerais, Rio de Janeiro e Goiás igual a $48.440 \mathrm{~m}^{2}$ e em São Paulo igual a $24.200 \mathrm{~m}^{2}$.

Alqueire do Norte - s.m. Medida equivalente a $27.225 \mathrm{~m}^{2}$.

Alqueire do Pará - s.m. Medida correspondente a 30 quilos.

Alvoroço - s.m. 1. Gritaria, balbúrdia, bagunça. 2. Cio.

Alvoroçado - adj. e part. Diz-se de fêmea quando se encontra no cio. ${ }^{8}$

Anil-bravo - s.m. Nome de várias espécies do gênero Tephrosia, da família das leguminosas, usado para envenenar peixes em rios, represas e lagoas. Anileira-verdadeira - s.f. Arbusto da família das leguminosas, de flores rosadas, da qual se extrai anil de qualidade.

4 Conforme Houaiss (2001), arbusto da família das bixáceas (Cochlospermum insigne), nativo do Brasil, encontrado de PE a MG, em SP e no C.-O.). Também registra a seguinte variante butua.

5 Planta (Hibiscus bifurcatus), segundo Houaiss (2001).

6 Tecido de algodáo, leve ou de baixa qualidade, de acordo com Houaiss (2001).

7 Em Houaiss (2001), entendemos tratar-se de resina extraída do lentisco, cujas propriedades medicinais faz com que seja usada para mascar ou para fazer incenso e verniz.

8 Na própria fonte, a acepção aparece atrelada ao gênero feminino, apesar de o adjetivo estar na sua forma não feminina na subentrada do verbete. 
Anil-trepador - s.m. Planta trepadeira da família das vitáceas ( Cissus sicyoides), ornamental, cujo fruto produz tinta.

Anta - s.f. 1. Jogador bisonho. 2. adj. gir. Tolo, parvo. 3. RS. Sabido, sagaz. Argel - adj.2g. N. e NE. Descuidado, desmazelado, bagunceiro.

Argolaço - s.m. RJ. Argola grande. 2. Argolada. ${ }^{9}$

Armazenário - s.m. PE. Negociante de açúcar ou algodão.

Armazeneiro - s.m. 1. Quem armazena. 2. Dono de armazém.

Aroeira-branca - s.f. Arbusto da família das anacardiáceas, cujas folhas são aromáticas e medicinais e cujos frutos fornecem óleo; aroeira-brava; aroeirinha.

Aroeira-brava - s.f. 1. Aroeira-branca. 2. Aroeira-de-bugre.

Aroeira-da-praia - s.f. Arbusto originário da Europa, da família das anacardiáceas, de flores amarelas ou avermelhadas, de cujo fruto extrai-se óleo, usado na medicina, na iluminação e na indústria de sabão e de cujo lenho obtém-se carvão.

Aroeira-de-bugre - s.f. Arbusto da família das anacardiáceas, de flores branco-esverdeadas, de cuja casca obtém-se o azeite-de-aroeira, usado na medicina; aroeirinha-preta.

Aroeirinha - s.f. Aroeira-branca.

Aroeirinha-preta - s.f. Aroeira-de-bugre.

Arrebita-rabo - s.f. Sabiá-do-campo.

Arrobação - s.f. N e NE Arrobamento. ${ }^{10}$

[Arrobação] u.f. De boa arrobação. - N. e NE. Diz-se do gado que tem bastante peso e muita carne.

Arrozalva - s.f. Farinha de arroz.

Arroz-bravo - s.m. Abatiapé. ${ }^{11}$

Arroz-crioulo - s.m. Arroz feito com alho, cebola e caldo de carne, bem refogado, para que fique bem dourado.

Arroz-d'água - s.m. SC. Arrozeira. ${ }^{12}$

9 Ainda segundo Vargens (2007), “ batida com argola, batida com argola da aldraba (argola metálica com que se bate às portas)".

10 De acordo com Vargens (2007), arrobação e sua variante morfológica arrobamento se referem ao ato de "pesar por arroba", constituindo a arroba "antiga medida de peso hoje equivalente a $15 \mathrm{~kg}$ " e, ainda, "medida de capacidade para líquidos”.

11 Planta (Leersia hexandra), conforme informa Houaiss (2001).

12 Em Santa Catarina, processo de cultivo de arroz, com canalização de água para submersão 
Arroz-de-carreteiro - s.m. Prato típico gaúcho, composto de arroz, carne-seca, paio e temperos variados.

Arroz de casca - s.2g. Pessoa extremamente sensível.

Arroz de cuxá - s.m. Arroz cozido em água e sal, servido acompanhado de cuxá, molho à base de gengibre e outros temperos.

Arroz de festa - s.m. 1. Indivíduo que não perde festas. 2. Indivíduo que frequenta festas sem ser convidado; peru-de-festa; arroz-doce de festa; arroz-doce de pagode.

Arroz de função - s.m. arroz-doce.

Arroz de hauçá - s.m. NE. BA. Prato típico da Bahia e do nordeste do Brasil, introduzido pelos negros muçulmanos, composto de arroz branco com sal, carne-seca, alho e cebola. Var. arroz-de-auçá.

Arroz-de-rato - s.m. Vegetal da família das crassuláceas Sedum albecam.

Arroz de viúva - s.m. Arroz feito com sal e leite de coco.

Arroz-doce de festa - s.m. pop. Arroz de festa.

Arroz-doce de pagode - s.m. Arroz de festa.

Arrozeira - s.f. SC. Maneira de cultivo de arroz de forma que as ribeiras são canalizadas para submersão das plantas.

Arrozeiro - adj. Relativo à plantação de arroz.

Atalaia - s.2g. O morro mais alto de uma região.

Azarado - adj. e s.m. Que ou aquele que tem azar.

Azeite - s.m. pop. Ato de namorar.

Azeitado - adj. PE. pop. Aborrecido, zangado.

Azeitáo - adj. 1. Diz-se do bovino de pelo preto brilhante. 2. s.m. Óleo de mamona.

Azeite-de-cheiro - s.m. Óleo proveniente do dendê; azeite de dendê.

Azeite de dendê - s.m. Azeite-de-cheiro.

Azeite de luz - s.m. Óleo de rícino.

Azeiteira - s.f. pop. Namoradeira. ${ }^{13}$

Azeiteiro - adj. pop. Namorador. ${ }^{14}$

do terreno, de acordo com Houaiss (2001).

13 Apesar de trazerem o mesmo significado, de "pessoa muito namoradeira", na própria fonte encontramos entradas diferentes, de classes e gêneros diferentes, azeiteira (s.f) e azeiteiro $(\mathrm{adj} . \mathrm{m})$, o que creditamos às demais acepçóes que os termos apresentam, não relacionadas exclusivamente, entretanto, com o português brasileiro.

14 Cf. nota anterior. 
Azeitinho - s.m. Óleo de rícino.

Azeitona-da-terra - s.f. Vegetal da família das litráceas, cuphea pseudovaccinium, de bagas comestíveis.

Azeitona-do-mato - s.f. Árvore da família das mirbináceas, rapanea ferruginea.

Azougue - s.m. Planta da família das euforbiáceas.

Azougue-do-brasil - s.m. Abobrinha; abobrinha-do-mato.

Azougue-dos-pobres - s.m. Abobrinha; cipó-azougue.

Azuladinha - s.f. pop. Cachaça; azulinha.

Azulão - s.m. Pássaro de belo canto, cujas penas são azuis.

Bairro - s.m. MG. Pequeno povoado, arraial.

Bairrista - adj. 2g. e s. 2g. Que ou aquele que defende cegamente sua terra e menospreza os demais.

Baque - s.m. Momento, instante. ${ }^{15}$

Benjoim - s.m. Mandaguari. ${ }^{16}$

Benjoeiro - s.m. Planta que produz uma resina usada na perfumaria e na farmácia e cuja madeira serve para a construção civil.

Berinjela - s.f. Planta originária da Índia cujo fruto é usado na alimentação humana.

Berinjela-branca - s.f. Tipo de berinjela, cujos frutos são curvos.

Berinjela-brissial - s.f. Tipo de berinjela, cujos frutos são oblongos.

Bodoqueiro - s.f. Aquele que atira de bodoque.

Cabide - s.m. Cavalo magérrimo.

Cabide ambulante - pop. Pessoa macérrima.

Cabide de empregos - Pessoa que tem muitos empregos.

Cacifar - v. int. Recolher, no jogo, o cacife. ${ }^{17}$

Cacifeiro - s.m. Indivíduo que recolhe os cacifes.

Café-beirão - s.m. Café-do-Pará.

Café-bravo - Pequiá-café. ${ }^{18}$

15 Segundo Houaiss (2001), as acepçóes de "barulho de queda ou batida de um corpo"; "queda" "contratempo", "desconfiança” e "intuição" datam do século XV e náo são exclusivas do português do Brasil.

16 Segundo Houaiss (2001), abelha da família dos apídeos (Scaptotrigona postica), encontrada no interior do Brasil.

17 Valor com que cada jogador ingressa numa partida, de acordo com Vargens (2007).

18 Segundo Houaiss (2001), arbusto nativo do Brasil (Palicourea longepedunculata). 
Café-caneca - s.m. pop. Bar mal frequentado.

Café com isca - s.m. CE. Café com mistura.

Café com leite - 1. adj. 2g. 2n. pop. Que é bege. 2. s.2g. pop. Pessoa insignificante. 3. Na política brasileira, poder paulista e mineiro.

Café-comprido - s.m. Café-ralo.

Café-concerto - s.m. Lugar onde a plateia bebe ao som de canções; café-cantante.

Café-conosco - s.m. Café com mistura.

Café de duas mãos - s.m. Café com mistura.

Café-do-mato - s.m. Designação de plantas da família das apocináceas.

Café-do-pará - s.m. Cipó da família das leguminosas, encontrado nas capoeiras e à beira-rio.

Café-gordo - s.m. NE. Café com mistura.

Cafeicultor- s.m. Proprietário de lavoura de café.

Cafeicultura - s.f. Plantação de café.

Cafelana - s.f. Grande cafezal.

Cafelista - s.2g. Cafezista.

Cafeocracia - s.f. Domínio político nas mãos dos cafeicultores prósperos.

Café-pequeno - Cafezinho.

Caferana - s.f. Arvoredo das matas úmidas.

Cafezinho - s.m. 1. MT. Jaçanã. ${ }^{19}$ 2. Nome comum de diversas espécies vegetais.

Cafezista - s.2g. Cafeicultor.

Calibrado - adj. 1. Diz-se do pneu a que se deu a pressão de ar adequada. 2. Embriagado.

Calibrar - v.t.d. Dar a pressão adequada ao pneu.

Calibrina - s.f. gír. Cachaça.

Caneco - s.m. pop. Diabo, chefe dos gênios.

[Caneco] u.f. Pintar os canecos - Fazer bagunça, confusão.

Chué - adj.2g. Diz- se do traje ordinário.

Cuscuz - s.m. 1. Iguaria à base de farinha de milho ou de farinha de arroz, cozida no vapor. 2. RJ. Bolinho de farinha de milho ou de tapioca assado na grelha. 3. PE. Morro isolado.

19 De acordo com Houaiss (2001), ave (Jacana jacana). 
Cuscuzeira - s.f. Cuscuzeiro.

Cuscuzeiro - s.m. Forma para se fazer cuscuz; cuscuzeira.

Cuscuz-paulista - s.m. Cuscuz de fubá, feito com peixe e camarão, ou galinha, ovos cozidos e variados temperos.

Damasqueiro - s.m. Árvore de damasco.

Espinafração - s.f. Advertência severa.

Espinafrar - v.t.d. gír. Advertir severamente; decompor.

Espinafre-da-Guiana - AM. Arbusto da família das fitolacáceas (Phytolocaicosandra).

Fardão - s.m. Veste dos membros da Academia Brasileira de Letras.

[Fateixa] u.f. Espiar a fateixa ${ }^{20}-$ RS. Ancorar.

Fatia de parida - s.f. N. e NE. e LUS. Rabanada.

Fulano dos anzóis - s.m. fam. Fulano.

Fulano dos anzóis carapuça - s.m. fam. Fulano.

Fulano dos grudes - s.m. fam. Fulano.

[Garrafa] u.f. Conversar com a garrafa - pop. Ficar embriagado.

Garrafada - s.f. Remédio caseiro.

Garrafeiro - s.m. Comprador de garrafas.

Ginete - s.m. 1. NE. Sela dos vaqueiros 2. s. Indivíduo que é bom cavaleiro.

Girafa - s.f. Haste na qual se prende o microfone.

Giz - s.m. NE. Traço, a ferro quente, usado para marcar o gado.

Jasmim-de-cachorro - s.m. SP. Fezes caninas secas; jasmim do campo.

Jasmim do campo - s.m. NE. e MG. Jasmim-de-cachorro.

Jasmim-do-imperador - s.m. Flor-do-imperador. ${ }^{21}$

Jasmim-do-mato - s.m. Arbusto amazônico da família das apocináceas Peschiera latiflora.

Jasmim-laranja - s.m. Arbusto asiático da família das rutáceas Murraya exotica, usada na ornamentação.

Jasmim-manga - s.m. Arbusto da família das apocináceas Plumeria rubra, muito abundante no Brasil.

20 De acordo com Houaiss, fateixa é um brasileirismo de uso no NE, referindo-se a uma pedra utilizada como âncora nas jangadas de pescadores nordestinos".

21 Arbusto da família das oleáceas (Osmanthus fragrans), nativo do Japão, segundo Houaiss (2001). 
Jasmim-porcelana - s.m. Arbusto da família das apocináceas Peschiera coronaria, usada na ornamentação, semelhante ao jasmim do mato.

Jasmim-verde - s.m. Arbusto da família das solanáceas Cestrum nocturnum, usada na ornamentação cujas flores exalam um forte perfume à noite.

Jasmim-vermelho - s.m. Flor-de-coral.

Lacre-branco - s.m. Arbusto da família das melastomatáceas, de folhas compridas e flores muito pequenas.

Lacraia - s.f. Nome comum dado aos artrópodes miriápodes, quilópodes, com aproximadamente 200 espécies no Brasil.

[Lacraia] u.f. Ter lacraia no bolso - fam. Ser avarento, miserável.

Laranja-amarga - s.f. Laranja-da-terra.

Laranja-aperu - s.f. Laranja silvestre do Paraná.

Laranja-azeda - s.f. Laranja-da-terra.

Laranja-cravo - s.f. Tangerina; tangerineira.

Laranja-da-baía - s.f. Variedade brasileira de laranja e de laranjeira.

Laranja-da-china - s.f. Variedade brasileira de laranja e de laranjeira.

Laranja-da-terra - s.f. Variedade brasileira de laranja e de laranjeira, cujos frutos são usados para doce; laranja-amarga.

Laranja-de-umbigo - s.f. Laranja-da-baía.

Laranja-do-mato - s.f. Variedade de laranja e de laranjeira.

Laranja-do-natal - s.f. Variedade de laranja e de laranjeira, cujos frutos amadurecem pela ocasião do Natal.

Laranja-mimosa - s.f. Tangerina; tangerineira.

Laranjão - s.m. Determinada raça bovina do Piauí.

Laranja pêra - s.f. Variedade de laranja e de laranjeira.

Laranjeiro - s.m. Vendedor ou plantador de laranjas.

Laranjinha - s.f. 1. Espinho-de-vintém. ${ }^{22}$ 2. Cachaça com casca de laranja.

3. NE Limão de cheiro.

Laranjinha-do-campo - s.f. Bacupari-do-campo. ${ }^{23}$

Laranjinha-do-mato - s.f. Árvore das famílias das Rutáceas oriunda do Espírito Santo.

22 Árvore da família das rutáceas, encontrada em todo o Brasil (Zanthoxylum rhoifolium), de acordo com Houaiss (2001).

23 Segundo Houaiss (2001), arbusto nativo do cerrado do Brasil, encontrado da BA até SP (Salacia campestris). 
Lilás-da-Índia - s.m. Cinamomo.

Limada - s.f. Refresco de lima.

Limão-bravo - s.m. Fruta-de-cachorro.

Limão-canudo - s.m. Iraxim. ${ }^{24}$

Limão-de-caiena - s.m. Bilimbi. ${ }^{25}$

Limão-de-cheiro - s.m. Pequena esfera oca, de cera ou de borracha, cheia de água perfumada, usada nos festejos do entrudo.

Limão-do-mato - s.m. Limão-bravo.

Limão-francês - s.m. Arvoreta ornamental, natural da China.

Limão-galego - s.m. Arbusto da família das rutáceas, espinhoso e aromático.

Limãorana - s.m. Árvore da família das moráceas.

Limãorana-da-várzea - s.m. Arbusto da família das rubiáceas.

Limãoranazinho - s.m. Pequena árvore da família das rubiáceas.

Limãozinho - s.m. 1. Nome genérico de algumas plantas no Brasil. 2. fam. Batida-de-limão.

Loque - s.m. Lambedor. ${ }^{26}$

Magazine - s.m. Publicação periódica, ilustrada e recreativa.

Mameluco - s.m. Mestiço de índio com branco.

Marabuto - s.m. Alcunha pejorativa dada aos portugueses.

Marfim - s.m. 1. Pau-marfim. ${ }^{27}$ 2. Bucho-de-boi. ${ }^{28}$

Marfim-vegetal - s.m. Jarina. ${ }^{29}$

Maroma - s.f. AM. Armação sobre o qual se edificam habitações, palafita.

Marombar - v. int. Usar a maromba ${ }^{30}$ para movimentar a barca.

Marombeiro - s.m. RJ. pop. Aquele que frequenta assiduamente acade-

24 Abelha social, da subfamília dos meliponídeos, encontrada em boa parte do território brasileiro, conforme Houaiss (2001).

25 Árvore da família das oxalidáceas (Averrhoa bilimbi), cuja origem, incerta, pode ser brasileira ou malaia, de acordo com Houaiss (2001).

26 De acordo com Houaiss (2001), "medicação caseira".

27 Designação de diferentes árvores brasileiras (Agonandra brasiliensis; balfourodendron riedelianum; Connarus fulvus) ou não (Melochia umbellata), conforme Houaiss (2001).

28 Árvore nativa do sudeste brasileiro (Zeyheria tuberculosa), de acordo com Houaiss (2001).

29 Segundo Houaiss (2001), termo designativo de duas palmeiras, a Phytelephas macrocarpa, nativa da AM, e a microcarpa, nativa do Suriname e do Brasil (AM).

30 Vara utilizada para manter o equilíbrio, de acordo com Houaiss (2001). 
mias de ginástica ou faz ginástica particularmente.

Marombista - adj.2g. e s.2g. 1. Diz-se de ou indivíduo que não cumpre compromissos. 2. Diz-se ou participante do grupo político que não se definiu pelos moderados, pelos exaltados, nem pelos restauradores, no período regencial brasileiro.

Marrão - s.m. Leitão desmamado.

Marrote - s.m. Porco pequeno, não castrado.

Mascarado - adj. e part. gír. Profissional de mérito, todavia convencido, pernóstico.

Mascarar - v.t.d. gír. Tornar-se fingido.

Matraca - s.f. 1. Tagarela. 2. Martin-pescador-grande. ${ }^{31}$ 3. gír. Metralhadora. 4. gír. Qualquer tipo de arma de fogo.

Matraca-da-quaresma - s.f. SP fam. Tagarela.

Matracolejante - adj.2g. Que matracoleja.

Matracolejar - v.int. Soar como matraca. ${ }^{32}$

Matraquear - Conversar fiado.

Monção - s.f. Expedição que trafega pelos rios de São Paulo e do Mato Grosso, nos séculos XVIII e XIX.

Múmia - s.f. fig. Indivíduo sem energia.

Papagaiada - s.f. pop. Exibição exagerada; papagaíce.

Papagaiado - adj. Diz-se do animal de sela que inclina mãos, ao andar, uma de encontro à outra.

Papagainho-roxo - s.m. Maitaca-roxa. ${ }^{33}$

Papagaio-caboclo - s.m. Papagaio-peito-roxo.

Papagaio-campeiro - s.m. Ave psitaciforme, da família dos psitacídeos Amazona ochrocephala (Gmel.), cujo habitat é o NO do Brasil e países limítrofes.

Papagaio-curraleiro - s.m. Papagaio-peito-roxo.

Papagaio-da-serra - s.m. Ave psitaciforme, da família dos psitacídeos Amazona preteri (Tem.), cujo habitat é o Uruguai e S do Brasil.

31 Houaiss (2001) informa tratar-se de pássaro (Ceryle torquata) encontrado do México à Terra do Fogo.

32 Em Vargens (2007), vemos que matraca é instrumento de percussão em forma de prancheta que traz argolas de ferro ou tábuas presas a ela e contra a qual batem, produzindo estalos.

33 Ave da família dos psitacídeos (Pionus menstruus), encontrado da Costa Rica à Bolívia e ao SE do Brasil, de acordo com Houaiss (2001). 
Papagaio-de-coleira - s.m. Anacã. ${ }^{34}$

Papagaio-do-mangue - s.m. Ave psitaciforme, da família dos psitacídeos Amazona amazonica (L), cujo habitat é o $\mathrm{N}$ e C do Brasil e países limítrofes.

Papagaio-do-peito-roxo - s.m. Psitaciforme, da família dos psitacídeos Amazona vinacea (kuhl.), cujo habitat é o S e E do Brasil.

Papagaio-grego - s.m. Papagaio-verdadeiro.

Papagaio-poaieiro - s.m. Papagaio-do-mangue.

Papagaio-urubu - s.m. Periquito-urubu.

Papagaio-verdadeiro - s.m. Psitaciforme, da família dos psitacídeos Amazona aestiva (L.), cujo habitat é o E do Brasil.

Rincão - s.m. RS. Qualquer lugar da campanha gaúcha onde haja riacho, mata etc.

Safra - s.f. NE. Época do aparecimento de um grande cardume. 2. RS. Época em que normalmente se vendem o gado gordo e alguns produtos oriundos da pecuária, tais como lâ, charque etc.

Safreiro - s.m. Aquele que trabalha somente na época da safra.

Saguão - s.m. ant. bras. e provincianismo lus. Pequeno cômodo de entrada, de onde sai a escadaria que leva ao(s) andar(es) superior(es).

Sofá-bicama - s.m. Bicama.

Sofá-cama - s.m. Sofá dobradiço que pode servir de sofá e de cama.

Sofá-de-arrasto - s.m. NE. pop. Esteira.

Sultão-dos-matos - s.m. Espírito do mato, entidade mitológica, folclórica ameríndia.

Tabica- s.f. Vegetal de hastes finas e flexíveis.

Tabicada - s.f. Pancada com tabica. ${ }^{35}$

Tafoneiro - s.m. Variante fonética de atafoneiro, isto é, dono ou quem dirige atafona. ${ }^{36}$

Taifa - s.f. Designação comum ao pessoal subalterno das especialidades de cozinheiro, barbeiro, padeiro e arrumador (copeiro), camaroteiro etc.

Taipa - s.f. Parede de cal e areia ou barro.

Taipeiro - adj. NE. Prato abarrotado de comidas diversas.

Tambor-onça - s.m. Cuíca.

\footnotetext{
34 Aindroptyus accipitrinus, nativa da AM.

35 Chicote feito com o referido vegetal, de acordo com Houaiss (2001).

36 Moinho de água movido por animais, segundo a própria fonte (VARGENS, 2007).
} 
Tambor-de-Mina - s.m. Ritual e cerimônia, oriunda da antiga Costa do Ouro, cujas danças e cantos marcados por tambores.

Tarado - adj. 1. Que é sexualmente devassado. 2. gír. Fascinado; apaixonado.

Tarar - v.i. 1. Apaixonar-se. int. gír. 2. Agir como tarado.

Tareco - s.m. 1. PE. AL. Espécie de pão-de-ló em rodelas. 2. GO. Bolo frito. 3. MG. Caminho ruim.

Tarecagem - s.f. Grande quantidade de tarecos. ${ }^{37}$

Tarecama - s.f. Tarecagem.

Tarefa - s.f. Medida agrária constituída por terras ocupadas por canaviais.

Tarimba - s.f. Larga experiência; grande prática.

Tarimbado - adj. Que tem experiência.

Tarrafa - s.f. N. Espécie de renda.

Tarrafear - v.int. e t.d. N. Segurar o rabo do boi, para derrubá-lo.

Tripa - s.f. NE. pop. Linguiça.

Tripa gaiteira - NE. pop. s.f. O intestino grosso.

Xadrez - s.m. Cela, cárcere, prisão.

Xaropada - s.f. Coisa enfadonha.

Xaropear - v.t.d. Aborrecer.

Xaveco - s.m. 1. Pessoa ou coisa sem importância. 2. gír. Patifaria

Zagaieiro - s.m. Pessoa que, armada de zagaia, acompanha o atirador para defendê-lo.

Zênite - s.m. Na astronomia, ponto em que a vertical superior de um lugar corta a esfera celeste acima do horizonte.

Zero-quilômetro - adj. 2g. e 2n. 1. Diz-se do veículo novo. 2. P. ext. Diz-se de alguma coisa ainda não usada.

A análise dos arabismos ibéricos cuja introdução no Brasil resultou em novas pronúncias, variantes morfológicas, expressões idiomáticas e, sobretudo, novos significados, mostra-nos que:

No que respeita à fonética, a fonte indica apenas 02 variantes brasileiras, caguete ( $\sim$ alcaguete) e tafoneiro ( $\sim$ atafoneiro), ambas aferéticas, próprias de usos não padrão da língua portuguesa, como, efetivamente, registra Vargens (2007) para a primeira, ao apresentá-la como "variante popular".

37 Ainda em Vargens (2007), encontramos para tareco a acepção de 'utensílio de pouco valor'. 
Observam-se variantes morfológicas, marcadas por morfemas derivacionais distintos, a exemplo de cafelista - cafezista - cafeicultor, eventualmente por morfema flexional de gênero, como cuscuzeiro - cuscuzeira "forma para se fazer cuscuz”, mas, sobretudo, por composição, seja por s. + adj., como laranja-amarga - laranja-azeda, seja por dois substantivos intermediados por preposição, seguida ou não de artigo, s. + prep. [+ art.] + s., laranja-da-terra ( - laranja-amarga). A diversidade estrutural das variantes é evidenciada, por exemplo, pelas formas café com isca (s. + prep. + s.) - café-conosco (s. + pron.) - café-de-duas-mãos (s. + prep. + num. + s.), todas designando "café com mistura".

Diferentemente dos arabismos ibéricos medievais, caracterizados pelo predomínio de formas básicas designativas de referentes do universo arábico-islâmico de Alandalus, os arabismos herdados do português europeu, no Brasil, são notadamente formas compostas (127 itens ou 46,3\% do total), mais do que o dobro das formas básicas (62 termos, 22,6\% dos vocábulos), e formas derivadas (78 arabismos, 28,5\% dos itens), ratificando a integração dos arabismos na língua portuguesa, uma vez que a sua disposição no sistema lexical da língua possibilita a formação destes novos itens lexicais.

Estes arabismos designam notadamente referentes do Brasil, sobretudo plantas e animais nativos, o que corroboram as variantes lexicais de origem indígena que muitos deles apresentam: aletria - manjuba, limão-canudo - iraxim (fauna); algodão-do-brejo - fanfä, arroz-bravo - abatiapé, café-bravo - pequiá-café, laranjinha-do-campo - bacupari-do-campo, limão-de-caiena - bilimbi, marfim-vegetal - jarina (flora).

A classe de palavras numericamente melhor representada pelo vocabulário analisado é a dos substantivos, com 245 itens ou 89,1\% do total, fato também verificado entre os arabismos medievais do português europeu, apresentando a literatura especializada, geralmente, um único verbo, recamar, e um adjetivo, mesquinho. No português brasileiro, entretanto, ocorrem 09 verbos (alcaguetar, calibrar, marombar etc.), perfazendo 3,3\% do vocabulário analisado, apenas uma locução adverbial (de açoite) e 20 adjetivos, equivalentes a 7,3\% das formas levantadas (como alvoroçado, azarado, bairrista, papagaiado e o híbrido zero-quilômetro).

A análise dos campos semânticos pelos quais se distribuem os arabismos europeus com usos próprios do Brasil aponta predomínio do campo semântico da flora e agricultura (94 itens ou 31,3\% do total), seguido da 
culinária (31 tens, $10,33 \%$ do total) e da fauna, pesca, pecuária e montaria (com 30 itens, perfazendo $10 \%$ do total das formas analisadas). Verificaram-se campos variados, como o de instrumentos musicais, de instrumentos e utensílios, de unidades de peso e medida, de coletivos e grandes quantidades, de geografia e acidentes geográficos, de substâncias medicinais, químicas ou de perfumaria, de engenharia, construção e habitação, de vida social, dentre outros.

\section{Considerações finais}

Retomando a questão norteadora deste estudo, se a lexicografia nacional documenta usos específicos do português brasileiro para arabismos herdados do português europeu, e a hipótese investigada, de que esta dicionarização efetivamente ocorre, uma vez tratar-se de empréstimos de antiga integração, facultando novos usos, a análise dos dados apenas exposta nos permite concluir pela corroboração da hipótese testada.

Com efeito, levantaram-se inicialmente 274 vocábulos, mas a análise do conteúdo semântico mostrou que a produtividade dos arabismos era tal que a dicionarização não atentava para a polissemia, obrigando-nos a ampliar o número de itens totais na análise estatística dos dados, na sua distribuição, por exemplo, em campos semânticos.

Evidencia-se, portanto, que os arabismos do português brasileiro ainda são passíveis de investigação, tanto das formas já dicionarizadas quanto daquelas que ainda não figuram nos dicionários, por não terem origem árabe reconhecida ou o seu uso específico no Brasil.

\section{Referências}

BLOOMFIELD, L. Language. Delhi: Motilal Banarsidass Publishers Private Ltd., 2005.

CÂMARA JR., J. M. Dicionário de linguistica e gramática: referente à língua portuguesa. 14. ed. Petrópolis: Vozes, 1988.

CORRIENTE, F. Diccionario de arabismos y voces afines en iberorromance. 2. ed. ampl. Madrid: Gredos, 2003. [Biblioteca Románica Hispánica, Fundada por Dámaso Alonso, Diccionarios, 22] 
DICMAXI Michaëlis, Moderno Dicionário da Língua Portuguesa, Versão 1.1. Amigo do Mouse Software Ltda., set. 2000. 1 CD-ROM.

DOUMA, N. Estudio en la Fraseologia. 2012. Tese (Mestrado em Linguística). Departamento de las Lenguas Latinas, Universidad de Orán, Orán.

FERREIRA, A. B. de H. Novo Aurélio século XXI: o dicionário da língua portuguesa. 3. ed. totalmente revista e ampliada. Versão 3.0. Rio de Janeiro: Lexikon Informática Ltda./Sonopress, 1999. 1 CD-ROM.

FREITAS, T.; RAMARILO, M.C.; SOALHEIRO, E. O processo de integração dos estrangeirismos no português europeu. In: Actas. Lisboa: Colibri, 2002. P.371-385. Disponível em HTTP://www.apl.org.pt/actas/xviii-encontro-nacional-da-associacao-portuguesa-de-linguistica.html ,13/12/2013.

HOUAISS, A.; VILLAR, M. de S. Dicionário Houaiss da língua portuguesa. Versão 1.0.10. Rio de Janeiro: Objetiva, 2006. 1 CD-ROM.

IORDAN, I.; MANOLIU, M. Manual de lingüistica románica. Revisión, reelaboración parcial y notas por Manuel Alvar. 2. reimpressión. Madrid: Gredos, 1989. v. II. p. 133-144. (Biblioteca Románica Hispánica, dirigida por Dámaso Alonso, III. Manuales, 29)

LÜDTKE, H. Historia del léxico románico. Versión española de Marcos Martínez Hernández. Madrid: Gredos, 1974.

MACHADO, J. P. Ensaios arábico-portugueses. Lisboa: Notícias, 1997.

MICHAËLIS: Moderno Dicionário da Língua Portuguesa. São Paulo: Melhoramentos, 1998.

NEUVONEN, E. K. Los arabismos de las Cantigas de Santa María. Boletín de Filología, 12, p. 291-352, 1951.

TEYSSIER, P. História da lingua portuguesa. Trad. por Celso Cunha. 2. ed. São Paulo: Martins Fontes, 2001. p. 43-44.

VARGENS, J. B. de M. Léxico português de origem árabe: subsídios para os estudos de filologia. Rio Bonito: Almádena, 2007.

VIGUERA MOLINS, M. J. Lengua árabe y lenguas románicas. Revista de Filología Románica, n. 19, p. 15-54, 2002. 


\title{
EUROPEAN ARABISMS IN BRAZILIAN PORTUGUESE
}

\author{
ABSTRACT \\ This paper about Arabic loans in Brazilian Portuguese \\ aims to identify local uses of the Iberian heritage, \\ registered as diasystemic information in the Léxico \\ Português de Origem Árabe (VARGENS, 2007). It \\ analyses the Arabisms structure as well as the parts of \\ speech and semantic fields they belong to.
}

KEYWORDS: Iberian Arabisms; Brazilian Portuguese; Lexicography.

Recebido em: 31/05/2016 Aprovado em: 20/10/2016 